\title{
Computing Vertex Degree-Based Multiplicative Version of Topological Indices for Tungsten Trioxide Nano Multilayer Structure in Nanotherapeutic Anti-Cancer Activity
}

\author{
M.S. Duraisami ${ }^{1}$ (D) , D. Benny Anburaj 2 (D) , K. Parasuraman 1,* (D) \\ 1 PG \& Research Department of Physics, Poompuhar College (Autonomous) (Affiliated to Bharathidasan University, \\ Tiruchirappalli), Melaiyur - 609107, Tamilnadu, India; tharmamithran@gmail.com (M.S.D.); resphy21@gmail.com \\ (K.P.); \\ 2 PG and Research Department of Physics, D. G. Govt. Arts College (Affiliated to Bharathidasan University, \\ Tiruchirappalli), Mayiladuthurai, Tamilnadu, India; bennyanburaj@ rediffmail.com (D.B.); \\ * Correspondence: resphy21@gmail.com;
}

Scopus Author ID 57191177573

Received: 18.03.2021; Revised: 10.05.2021; Accepted: 15.05.2021; Published: 18.06.2021

\begin{abstract}
Several research reports suggest that there is a strong interdependence among the molecular structure of chemical compounds and their physicochemical properties. The computation of the topological index of such a chemical structure facilitates researchers to gain more insight into the physical and bio-activity of chemical materials. In this article, we focus on $\mathrm{WO}_{3}$, which is a widely studied nanomaterial and is recently employed as an excellent cytotoxic agent towards the liver (Hep2 ) and the breast (MCF-7) cancerous cells. Various vertex degree-based multiplicative versions of topological indices for $\mathrm{WO}_{3}$ nano multilayer were computed using the edge partition technique. We also compared all of the indices graphically. The obtained results redress the lack of medical and chemical experiments, thus constructing the theoretical framework for the pharmacological field.
\end{abstract}

Keywords: multiplicative topological index; $\mathrm{WO}_{3}$; nano multilayer; molecular graph; cancer.

(c) 2021 by the authors. This article is an open-access article distributed under the terms and conditions of the Creative Commons Attribution (CC BY) license (https://creativecommons.org/licenses/by/4.0/).

\section{Introduction}

A molecular graph $G$ with the set $V$ of vertices and the set $E$ of edges is a connected, finite, undirected, loopless graph without parallel edges. The number of neighbors of a vertex $u \in V(G)$ is said to be the degree of $u$ that is $d_{u}$. The edge between the vertices $u$ and $v$ of $V(G)$ is denoted by $e=u v \in E(G)$.

\subsection{A brief sketch on topological indices and cancer nanotechnology.}

With the advancement in pharmacopeia, a myriad of drugs emerged every year from various countries. Before bringing these drugs into force, many clinical trials are needed to reveal their toxicity, bioactivity and degree of risk effects on the human body. However, it seems to be a herculean task for economically weaker nations due to their inadequate laboratory conditions. To overcome these difficulties, the chemical graph-theoretic approach has evolved to predict the physicochemical and biological behavior of the newly proposed drugs, thus saving time and reducing the workload and cost [1]. Topological indices are the numerical 
values of a molecular graph that are helpful for drug designing in pharmacological science. In the recent past, several degree-based multiplicative topological indices were computed to analyze the characteristics of different drugs and compounds, which are widely used in chemical and pharmacy engineering [2-8].

Cancer is a deadly disease that has the second-highest mortality rate in the world. Moreover, cancer is accountable for 9.6 million deaths in 2018 and the cases estimated to 29.4 million in 2040 [WHO report on cancer, 2020]. Liver, stomach, colon, breast, and lung cancers increase cancer deaths every year. Many successful medical practices and conventional treatments (e.g., hormonal therapy, chemotherapy, etc.) are more helpful to increase the life span of cancer patients. However, the lack of tumor selectivity and systemic toxicity has hindered many novel chemotherapeutic drugs in arriving at clinical translation. To address these issues, a large number of initiatives have been made by researchers in pharmaceutical engineering. Nanobiotechnology has redesigned the choice of treatments for people falling ill with a large number of diseases, especially cancer $[9,10]$. In recent times, metal oxide nanostructures have emerged as novel nanomedicine, incorporating nanodiagnostics and nanotherapeutics [11-23]. $\mathrm{WO}_{3}$ nanomaterial is one such important semiconducting metal oxide and is successfully employed as a cytotoxic agent towards liver (Hep-2) and the breast (MCF-7) cancer cells [24-26]. It is worth mentioning that $\mathrm{WO}_{3}$ nanostructures are specifically harmful to cancer cells without damaging human ectocervical epithelial (HECE) healthy cells, which exhibit their selective killing behavior of cancerous cells and biocompatibility [24-26].

\subsection{Preliminaries.}

This section tabulated certain vertex degree-based multiplicative topological indices, which are constructing our main results. During the 1980s, Narumi and Katayama [27] have introduced a multiplicative topological index, namely, $\mathrm{NK}(\mathrm{G})$. Later $\mathrm{NK}(\mathrm{G})$ is reformulated as a general multiplicative index by Wang et al. [28]. In general, most of the multiplicative topological indices have the following general form [29]:

$$
\operatorname{MTI}(G)=\prod_{u v \in E(G)} F(d(u), d(v)) .
$$

Multiplicative Randić index is another important molecular descriptor, which provides many potential applications in the drug designing sector [34]. Kulli et al. [33] have introduced the first and second multiplicative generalized Zagreb indices, which are represented as $M Z_{1}^{\alpha}(G)$ and $M Z_{2}^{\alpha}(G)$, respectively.

Remark 1.2.1.

$M Z_{1}^{\alpha}(G)$ becomes a multiplicative version of first Zagreb index for $\alpha=1$; for $\alpha=2$, $M Z_{1}^{\alpha}(G)$ turns out to be a multiplicative first hyper Zagreb index and $M Z_{1}^{\alpha}(G)$ will be a multiplicative sum connectivity index if $\alpha=-\frac{1}{2}$.

Table 1. Formula for vertex degree-based multiplicative topological indices of a graph G.

\begin{tabular}{c|c|c|c} 
S.No & Topological Index & Notation & Formula of Topological Index \\
\hline 1. & Narumi - Katayama Index [27] & $N K(G)$ & $\prod_{u \in V(G)}\left(d_{u}\right)$ \\
\hline 2. & General Multiplicative Index [28] & $W_{1}^{\alpha}(G)$ & $\prod_{u \in V(G)}\left(d_{u}\right)^{\alpha}$
\end{tabular}




\begin{tabular}{|c|c|c|c|}
\hline S.No & Topological Index & Notation & Formula of Topological Index \\
\hline 3. & $\begin{array}{l}\text { First Multiplicative Zagreb Index } \\
\qquad[30]\end{array}$ & $I I_{1}(G)$ & $\prod_{u \in V(G)}\left(d_{u}\right)^{2}$ \\
\hline 4. & $\begin{array}{l}\text { Multiplicative version of First } \\
\text { Zagreb Index [31] }\end{array}$ & $I I_{1}^{*}(G)$ & $\prod_{u v \in E(G)}\left(d_{u}+d_{v}\right)$ \\
\hline 5. & $\begin{array}{l}\text { Second Multiplicative Zagreb Index } \\
\qquad[30]\end{array}$ & $I I_{2}(G)$ & $\prod_{u v \in E(G)}\left(d_{u} \cdot d_{v}\right)$ \\
\hline 6. & $\begin{array}{l}\text { Multiplicative First Hyper Zagreb } \\
\text { Index [32] }\end{array}$ & $H I I_{1}(G)$ & $\prod_{u v \in E(G)}\left(d_{u}+d_{v}\right)^{2}$ \\
\hline 7. & $\begin{array}{l}\text { Multiplicative Second Hyper Zagreb } \\
\text { Index [32] }\end{array}$ & $H I I_{2}(G)$ & $\prod_{u v \in E(G)}\left(d_{u} \cdot d_{v}\right)^{2}$ \\
\hline 8. & $\begin{array}{l}\text { First Multiplicative Generalized } \\
\text { Zagreb Index [33] }\end{array}$ & $M Z_{1}^{\alpha}(G)$ & $\int_{(G)}\left(d_{u}+d_{v}\right)^{\alpha}$ \\
\hline 9. & $\begin{array}{l}\text { Second Multiplicative Generalized } \\
\text { Zagreb Index [33] }\end{array}$ & $M Z_{2}^{\alpha}(G)$ & $\coprod_{(G)}\left(d_{u} \cdot d_{v}\right)^{\alpha}$ \\
\hline 10. & $\begin{array}{l}\text { Multiplicative Sum Connectivity } \\
\text { Index [34] }\end{array}$ & $\operatorname{SCII}(G)$ & $\prod_{u v \in E(G)} \frac{1}{\sqrt{d_{u}+d_{v}}}$ \\
\hline 11. & $\begin{array}{l}\text { Multiplicative Product Connectivity } \\
\text { Index (or) Multiplicative Randić } \\
\text { Index [34] }\end{array}$ & $\begin{array}{l}P C I I(G) \text { (or) } \\
\quad \operatorname{RII}(G)\end{array}$ & $\prod_{u v \in E(G)} \frac{1}{\sqrt{d_{u} \cdot d_{v}}}$ \\
\hline 12. & $\begin{array}{l}\text { Multiplicative Sum Connectivity } \\
\qquad \text { F-Index [32] }\end{array}$ & $\operatorname{SFII}(G)$ & $\prod_{u v \in E(G)} \frac{1}{\sqrt{d_{u}^{2}+d_{v}^{2}}}$ \\
\hline 13. & $\begin{array}{l}\text { Multiplicative Product Connectivity } \\
\qquad \text { F - Index [32] }\end{array}$ & $\operatorname{PFII}(G)$ & $\prod_{u v \in E(G)} \frac{1}{\sqrt{d_{u}^{2} \cdot d_{v}^{2}}}$ \\
\hline 14. & Multiplicative First F -Index [35] & $F_{1} I I(G)$ & $\prod_{u v \in(G)}\left[\left(d_{u}\right)^{2}+\left(d_{v}\right)^{2}\right]$ \\
\hline 15. & $\begin{array}{l}\text { Multiplicative Second F - Index } \\
\qquad[36]\end{array}$ & $F_{2} I I(G)$ & $\prod_{u v \in E(G)}\left[\left(d_{u}\right)^{2} \cdot\left(d_{v}\right)^{2}\right]$ \\
\hline 16. & $\begin{array}{l}\text { Multiplicative Atomic Bond } \\
\text { Connectivity Index [37] }\end{array}$ & $A B C I I(G)$ & $\prod_{u v \in E(G)} \sqrt{\frac{d_{u}+d_{v}-2}{d_{u} \cdot d_{v}}}$ \\
\hline 17. & Multiplicative Harmonic Index [38] & $H I I(G)$ & $\prod_{u v \in E(G)} \frac{2}{d_{u}+d_{v}}$ \\
\hline 18. & $\begin{array}{l}\text { Multiplicative Geometric Arithmetic } \\
\text { Index [37] }\end{array}$ & $G A I I(G)$ & $\prod_{u v \in E(G)} \frac{2 \sqrt{d u \cdot d_{v}}}{d_{u}+d_{v}}$ \\
\hline 19. & $\begin{array}{l}\text { General Multiplicative Geometric } \\
\text { Arithmetic Index [39] }\end{array}$ & $G A^{\alpha} I I(G)$ & $\prod_{u v \in E(G)}\left(\frac{2 \sqrt{d u \cdot d v}}{d_{u}+d_{v}}\right)^{\alpha}$ \\
\hline 20. & $\begin{array}{l}\text { Multiplicative Augmented Zagreb } \\
\text { Index [40] }\end{array}$ & $\operatorname{AZII}(G)$ & $\prod_{u v \in E(G)}\left(\frac{d_{u} \cdot d_{v}}{d_{u}+d_{v}-2}\right)^{3}$ \\
\hline
\end{tabular}

Remark 1.2.2.

$M Z_{2}^{\alpha}(G)$ turns out to be a second multiplicative Zagreb index for $\alpha=1$; for $\alpha=2$,

$M Z_{2}^{\alpha}(G)$ will be a multiplicative second hyper Zagreb index and $M Z_{2}^{\alpha}(G)$ becomes a multiplicative Randić index if $\alpha=-\frac{1}{2}$. 


\subsection{Aim of this work and roadmap.}

In this scenario, we have computed some important vertex degree-based multiplicative version of topological indices for $\mathrm{WO}_{3}$ nano multilayer through its molecular graph to disclose its underlying biological characteristics. In section 2 , the edge and the vertex set partitions were briefly discussed. In section 3 , we derive certain new results of $\mathrm{WO}_{3}$ nano multilayer according to the dimensions $\mathrm{m}, \mathrm{s}$ and $\mathrm{d}$, and compared all the indices graphically. In section 4, we explained the cytotoxic mechanism of $\mathrm{WO}_{3}$ nanostructures towards the liver (Hep-2) and the breast (MCF-7) cancerous cells.

\section{Materials and Methods}

For computing our main results, we applied the edge partition method, vertex partition method, combinatorial computing, analytic techniques, graph-theoretical tools and method of counting degrees. We employed Origin software to plot the graphical representation of all indices. The construction of $\mathrm{WO}_{3}$ molecular graph is well explained in our previous works [41,42]. Figure 1 represents a 3-D $\mathrm{WO}_{3}$ nano multilayer structure with $m$ rows, $s$ columns and $d$ layers and is represented by $W_{3}[m, s, d]$ where $m, s, d \geq 1$. W and $\mathrm{O}$ atoms were represented by big and small dots, respectively. It is very clear that $W O_{3}[m, s, d]$ has 1,2 and 6 degrees vertices, and the number of vertices are $4 m s d+6 d+15(m d+s d)+m s+m+s+1$. Moreover, the edge set of $\mathrm{WO}_{3}[m, s, d]$ has been partitioned into two disjoint sub-classes with respect to the degrees of the end vertices of each edge, namely, $\{1,6\}$ and $\{2,6\}$, and the number of edges are $6 d(m s+m+s+1)$. The vertices of $W O_{3}[1,1,1]$ with degrees $\{1,2,6\}$ were illustrated in

Figure 2. The degree-based edge partition and vertex partition of $\mathrm{WO}_{3}[m, s, d]$ were given in Table 2 and Table 3.

The edge set of $\mathrm{WO}_{3}[m, s, d]$ has the following two partitions:

$$
\begin{gathered}
E_{(1,6)}=\left\{e=u v \in E\left(W_{3}[m, s, d]\right) \mid d_{u}=1, d_{v}=6\right\} \\
E_{(2,6)}=\left\{e=u v \in E\left(W_{3}[m, s, d]\right) \mid d_{u}=2, d_{v}=6\right\} .
\end{gathered}
$$

The vertex set of $\mathrm{WO}_{3}[m, s, d]$ has the following three partitions:

$$
\begin{gathered}
V_{1}=\left\{v \in V\left(W O_{3}[m, s, d]\right) \mid d_{v}=1\right\}, \\
V_{2}=\left\{v \in V\left(W O_{3}[m, s, d]\right) \mid d_{v}=2\right\} \\
\text { and } V_{6}=\left\{v \in V\left(W O_{3}[m, s, d]\right) \mid d_{v}=6\right\} .
\end{gathered}
$$




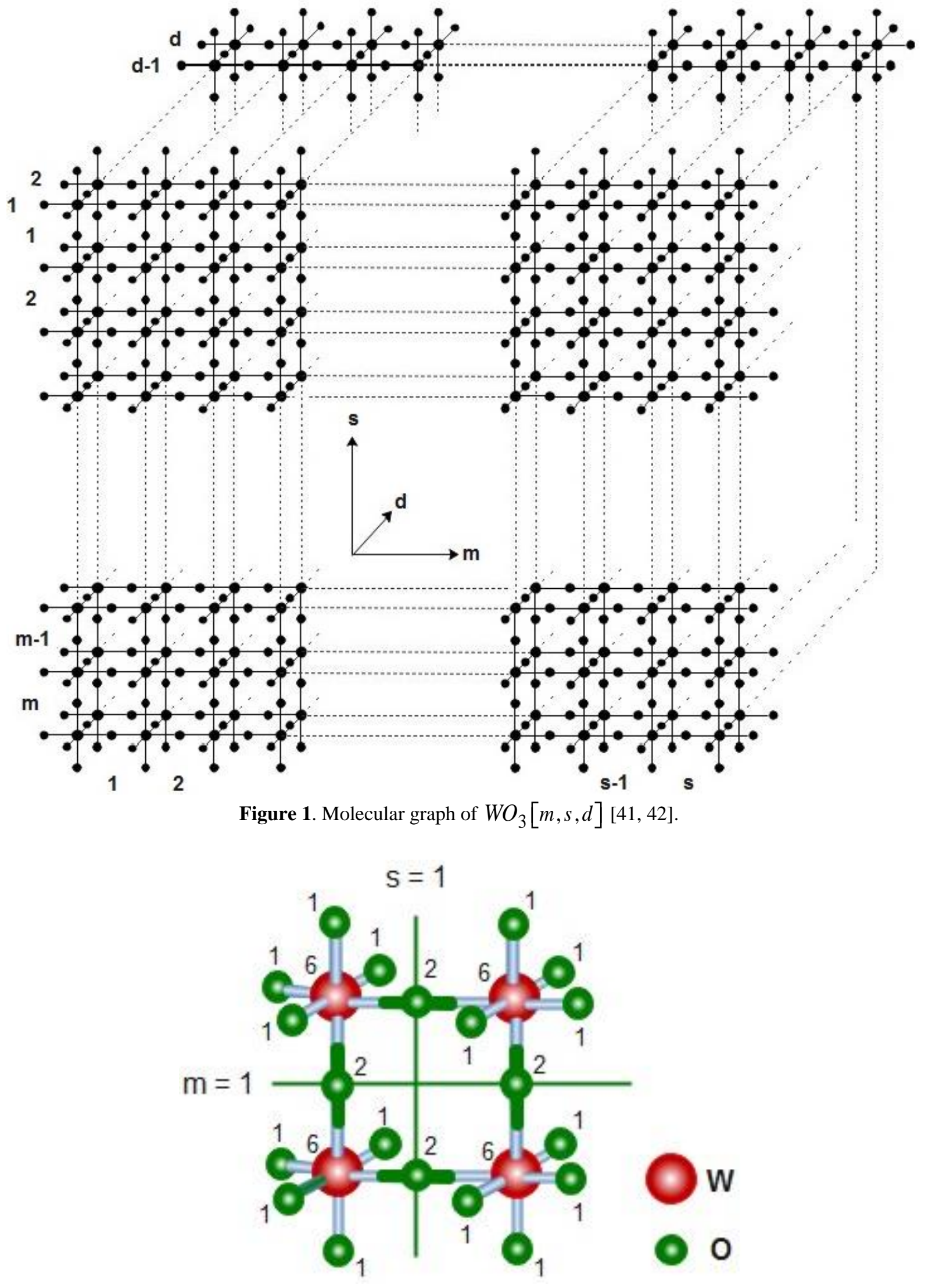

Figure 2. Vertices of $\mathrm{WO}_{3}[1,1,1]$ labelled with degrees $\{1,2,6\}[41,42]$. 
Table 2. Edge partition of $\mathrm{WO}_{3}[m, s, d]$ based on the degree of end vertices of every edge $[41,42]$.

\begin{tabular}{|c|c|c|}
\hline Type of edges & $E_{(1,6)}$ & $E_{(2,6)}$ \\
\hline$\left(d_{u}, d_{v}\right), u v \in E(G)$ & $(1,6)$ & $(2,6)$ \\
\hline $\begin{array}{l}\text { Number of } \\
\mid E_{\left(d_{u}, d_{v}\right) \mid}\end{array}$ & $2(m s+s d+m d+m+s+2 d+1)$ & $6 m s d+4(m d+s d)+2 d-2(m s+m+s+1)$ \\
\hline
\end{tabular}

Table 3. Vertex partition of $W O_{3}[m, s, d]$ based on the degree of end vertices of every edge $[41,42]$.

\begin{tabular}{l|c|c|c}
\hline $\begin{array}{l}\text { Vertex } \\
\text { partition } \\
V_{d_{u}}\end{array}$ & $V_{\mathbf{1}}$ & $V_{\mathbf{2}}$ & $\boldsymbol{V}_{\mathbf{6}}$ \\
\hline$d_{u}, u \in V(G)$ & 1 & 2 & \\
\hline $\begin{array}{l}\text { Number of } \\
\text { Vertices }\end{array}$ & $2(m s+s d+m d+m+s+2 d+1)$ & $3 m s d+2(m d+s d)-(m s+m+s+d+1)$ & $(m s+m+s+1) d$ \\
$\left|V_{d_{u}}\right|$ & & & \\
\hline
\end{tabular}

\section{Results and Discussion}

Theorem 3.1. Let $W O_{3}[m, s, d]$ be the $\mathrm{WO}_{3}$ nano multilayer of dimensions $m, s$, and $d \geq 1$. Then,

(1) $N K\left(W_{3}[m, s, d]\right)=2^{3 m s d+2(m d+s d)-(m s+m+s+d+1)} \times 6^{(m s+m+s+1) d}$.

(2) $W_{1}^{\alpha}\left(W O_{3}[m, s, d]\right)=2^{(3 m s d+2(m d+s d)-(m s+m+s+d+1)) \alpha} \times 6^{(m s+m+s+1) d \alpha}$.

(3) $I I_{1}\left(W O_{3}[m, s, d]\right)=2^{2(3 m s d+2(m d+s d)-(m s+m+s+d+1))} \times 6^{2(m s+m+s+1) d}$.

(4) $I I_{1}^{*}\left(W O_{3}[m, s, d]\right)=7^{2(m s+s d+m d+m+s+2 d+1)} \times 8^{6 m s d+4(m d+s d)+2 d-2(m s+m+s+1)}$.

(5) $\mathrm{II}_{2}\left(\mathrm{WO}_{3}[m, s, d]\right)=6^{2(m s+s d+m d+m+s+2 d+1)} \times 12^{6 m s d+4(m d+s d)+2 d-2(m s+m+s+1)}$.

(6) $\mathrm{HII}_{1}\left(\mathrm{WO}_{3}[m, s, d]\right)=7^{4(m s+s d+m d+m+s+2 d+1)} \times 8^{2(6 m s d+4(m d+s d)+2 d-2(m s+m+s+1))}$.

(7) $\mathrm{HII}_{2}\left(\mathrm{WO}_{3}[m, s, d]\right)=6^{4(m s+s d+m d+m+s+2 d+1)} \times 12^{2(6 m s d+4(m d+s d)+2 d-2(m s+m+s+1))}$.

(8) $M Z_{1}^{\alpha}\left(W O_{3}[m, s, d]\right)=7^{2(m s+s d+m d+m+s+2 d+1) \alpha} \times 8^{(6 m s d+4(m d+s d)+2 d-2(m s+m+s+1)) \alpha}$.

(9) $M Z_{2}^{\alpha}\left(W O_{3}[m, s, d]\right)=6^{2(m s+s d+m d+m+s+2 d+1) \alpha} \times 12^{(6 m s d+4(m d+s d)+2 d-2(m s+m+s+1)) \alpha}$.

(10) $\operatorname{SCII}\left(W_{3}[m, s, d]\right)=\left(\frac{1}{\sqrt{7}}\right)^{2(m s+s d+m d+m+s+2 d+1)} \times\left(\frac{1}{2 \sqrt{2}}\right)^{6 m s d+4(m d+s d)+2 d-2(m s+m+s+1)}$.

(11) $\operatorname{PCII}\left(W_{3}[m, s, d]\right)=\left(\frac{1}{\sqrt{6}}\right)^{2(m s+s d+m d+m+s+2 d+1)} \times\left(\frac{1}{2 \sqrt{3}}\right)^{6 m s d+4(m d+s d)+2 d-2(m s+m+s+1)}$.

(12) $\operatorname{SFII}\left(W_{3}[m, s, d]\right)=\left(\frac{1}{\sqrt{37}}\right)^{2(m s+s d+m d+m+s+2 d+1)} \times\left(\frac{1}{2 \sqrt{10}}\right)^{6 m s d+4(m d+s d)+2 d-2(m s+m+s+1)}$

(13) $\operatorname{PFII}\left(W_{3}[m, s, d]\right)=\left(\frac{1}{6}\right)^{2(m s+s d+m d+m+s+2 d+1)} \times\left(\frac{1}{12}\right)^{6 m s d+4(m d+s d)+2 d-2(m s+m+s+1)}$.

(14) $\mathrm{F}_{1} \Pi\left(W O_{3}[m, s, d]\right)=(37)^{2(m s+s d+m d+m+s+2 d+1)} \times(40)^{6 m s d+4(m d+s d)+2 d-2(m s+m+s+1)}$.

(15) $\mathrm{F}_{2} \Pi\left(W O_{3}[m, s, d]\right)=(36)^{2(m s+s d+m d+m+s+2 d+1)} \times(144)^{6 m s d+4(m d+s d)+2 d-2(m s+m+s+1)}$. 
(16) $\mathrm{ABC}\left(W O_{3}[m, s, d]\right)=\left(\sqrt{\frac{5}{6}}\right)^{2(m s+s d+m d+m+s+2 d+1)} \times\left(\sqrt{\frac{1}{2}}\right)^{6 m s d+4(m d+s d)+2 d-2(m s+m+s+1)}$.

(17) $\mathrm{HII}\left(W O_{3}[m, s, d]\right)=\left(\frac{4}{7}\right)^{2(m s+s d+m d+m+s+2 d+1)} \times\left(\frac{1}{4}\right)^{6 m s d+4(m d+s d)+2 d-2(m s+m+s+1)}$.

(18) $\operatorname{GAII}\left(W O_{3}[m, s, d]\right)=\left(\frac{2 \sqrt{6}}{7}\right)^{2(m s+s d+m d+m+s+2 d+1)} \times\left(\sqrt{\frac{3}{2}}\right)^{6 m s d+4(m d+s d)+2 d-2(m s+m+s+1)}$

(19) $\mathrm{GA}^{\alpha} \mathrm{II}\left(W O_{3}[m, s, d]\right)=\left(\frac{2 \sqrt{6}}{7}\right)^{2(m s+s d+m d+m+s+2 d+1) \alpha} \times\left(\sqrt{\frac{3}{2}}\right)^{(6 m s d+4(m d+s d)+2 d-2(m s+m+s+1)) \alpha}$

(20) $\mathrm{AZII}\left(\mathrm{WO}_{3}[m, s, d]\right)=(1.728)^{2(m s+s d+m d+m+s+2 d+1)} \times(8)^{6 m s d+4(m d+s d)+2 d-2(m s+m+s+1)}$.

Proof.

Using the values given in Table 2 and Table 3, one can arrive at the calculations according to the rules displayed in Table 1.

In order to determine the exact physicochemical behavior of multiplicative topological indices $\mathrm{WO}_{3}[m, s, d]$, logarithmic values of topological indices were computed and are plotted graphically in Figure 3. Among all the discussed multiplicative topological indices, ABC index has a higher correlation value than others (Table 4). Therefore, it could be inferred that the possibility of choosing a drug or a cytotoxic agent for initial clinical trials is simplified and the drug is chosen for anti-cancer activity be the one for which multiplicative topological ABC index has a greater coefficient of the correlation value. These findings will be very helpful for the preliminary laboratory processes in identifying the most effective as well as less harmful cytotoxic agents in cancer therapy.

\section{Anti-cancer activity of $\mathrm{WO}_{3}$ nanostructures}

According to literature, the cytotoxic activity of $\mathrm{WO}_{3}$ nanostructure on the liver (Hep2 ) and the breast (MCF-7) cancerous cells depend on several factors such as the generation of reactive oxygen species (ROS), electrostatic interaction between nanostructures and cancer cells, lipid peroxidation and oxidative stress [23-26]. As well as the possible cytotoxic mechanism of $\mathrm{WO}_{3}$ nanoarchitecture is explained as follows, due to the effect of electrostatic interactions, the $\mathrm{WO}_{3}$ nanostructures were easily attached to the outer cell membrane of the cancer cells. This electrostatic rupturing of the cell wall allows $\mathrm{WO}_{3}$ nanostructures to penetrate the cancer cell layer and attack the redox-active mitochondria. This leads to excessive generation of ROS and affects the antioxidant defenses resulting in oxidative stress. This phenomenon may cause apoptosis and damage to DNA which results in cell death. For more details, we refer to [23-26] and the references therein.

Table 4. Topological indices and their corresponding parameters.

\begin{tabular}{l|l|c|c}
\hline S.No. & \multicolumn{1}{|c|}{ Topological index } & $\begin{array}{c}\text { Karl Pearson's coefficient of } \\
\text { correlation (r) }\end{array}$ & Adj. $\mathbf{R}^{\mathbf{2}}$ \\
\hline 1. & Narumi - Katayama Index & 0.9994 & 0.9986 \\
\hline 2. & First Multiplicative Zagreb Index & 0.9994 & 0.9986 \\
\hline 3. & Multiplicative version of First Zagreb Index & 0.99983 & 0.99959 \\
\hline 4. & Second Multiplicative Zagreb Index & 0.99968 & 0.99925 \\
\hline 5. & Multiplicative First Hyper Zagreb Index & 0.99983 & 0.99959 \\
\hline
\end{tabular}




\begin{tabular}{l|l|c|c}
\hline S.No. & \multicolumn{1}{|c|}{ Topological index } & $\begin{array}{c}\text { Karl Pearson's coefficient of } \\
\text { correlation (r) }\end{array}$ & ${\text { Adj. } \mathbf{R}^{\mathbf{2}}}$ \\
\hline 6. & Multiplicative Second Hyper Zagreb Index & 0.99968 & 0.99925 \\
\hline 7. & Multiplicative Sum Connectivity Index & -0.99983 & 0.99959 \\
\hline 8. & Multiplicative Randić Index & -0.99968 & 0.99925 \\
\hline 9. & Multiplicative Sum Connectivity F -Index & -0.99985 & 0.99964 \\
\hline 10. & Multiplicative Product Connectivity F - Index & -0.99968 & 0.99925 \\
\hline 11. & Multiplicative First F - Index & 0.99985 & 0.99964 \\
\hline 12. & Multiplicative Second F - Index & 0.99968 & 0.99925 \\
\hline 13. & Multiplicative Atomic Bond Connectivity Index & 0.99996 & 0.9999 \\
\hline 14. & Multiplicative Harmonic Index & -0.99981 & 0.99955 \\
\hline 15. & Multiplicative Geometric Arithmetic Index & -0.99994 & 0.99985 \\
\hline 16. & Multiplicative Augmented Zagreb Index & 0.99907 & 0.99784 \\
\hline
\end{tabular}
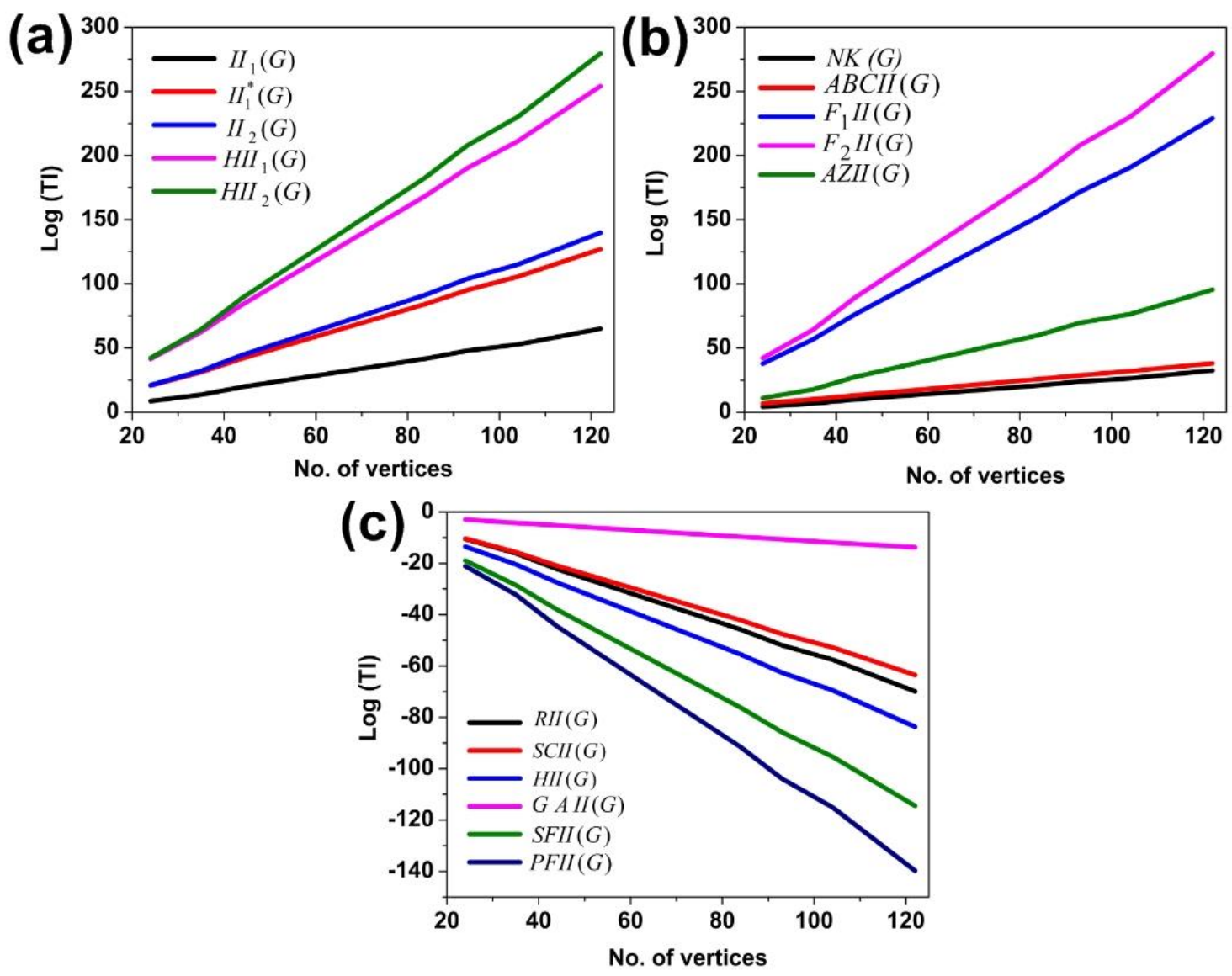

Figure 3. (a-c) Comparison of logarithmic values of various topological indices with respect to a number of vertices in $\mathrm{WO}_{3}[m, s, d]$.

\section{Conclusions}

We have computed the vertex degree-based multiplicative version of topological indices for the WO3 nano multilayer structure and derived accurate expressions for them. All the reported indices were compared graphically. From a well-being perspective, the obtained theoretical results will benefit the persons working in the pharmaceutical drug designing sector, especially those who encounter $\mathrm{WO}_{3}$ nanostructures for cancer therapy and also used in molecular data mining.

\section{Funding}

There was no financial support for this research. 


\section{Acknowledgments}

This research has no acknowledgments.

\section{Conflicts of Interest}

The authors declare no competing interests.

\section{References}

1. Trinajstić, N. Chemical graph theory, 2nd ed.; CRC Press; New York, USA, 1992, 1-352. https://doi.org/10.1201/9781315139111.

2. Gao, W; Wang, Y; Basavanagoud, B; Jamil, M.K. Characteristics Studies of Molecular Structures in Drugs. Saudi Pharmaceutical Journal 2017, 25, 580-586, https://doi.org/10.1016/j.jsps.2017.04.027.

3. Jahanbani, A; Shao, Z; Sheikholeslami, S.M. Calculating degree based multiplicative topological indices of Hyaluronic Acid - Paclitaxel conjugates' molecular structure in cancer treatment, Journal of Biomolecular Structure and Dynamics 2020, 1-10, https://doi.org/10.1080/07391102.2020.1800512.

4. Shao, Z; Jahanbani, A; Sheikholeslami, S.M. Multiplicative Topological Indices of Molecular Structure in Anticancer Drugs, Polycyclic Aromatic Compounds 2020, 1-15, https://doi.org/10.1080/10406638.2020.1743329.

5. Cancan, M; Mondal, S; De, N; Pal, A. Multiplicative degree based topological indices of some chemical structures in drug. Proyecciones 2020, 39, 1347-1364, https://doi.org/10.22199/issn.0717-6279-2020-050082.

6. Wang, X.L; Liu, J.B; Jahanbani, A; Siddiqui, M; Rad, N; Hasni, R. On generalized topological indices of silicon-carbon. Journal of Mathematics 2020, 1-21, https://doi.org/10.1155/2020/2128594.

7. Kang, S.M; Zahid, M.A; Virk, A. ur R; Nazeer, W; Gao, W. Calculating the degree-based topological indices of dendrimers. Open Chemistry, 2018, 16, 681-688, https://doi.org/10.1515/chem-2018-0071.

8. Gao, W; Wang, W.F; Farahani, M.R. Topological Indices Study of Molecular Structure in Anticancer Drugs. Journal of Chemistry, 2016, 1-8, https://doi.org/10.1155/2016/3216327.

9. Qi, B; Wang, C; Ding, J; Tao, W. Editorial: Applications of Nanobiotechnology in Pharmacology. Front. Pharmacol. 2019, 10, 1451, https://doi.org/10.3389/fphar.2019.01451.

10. Zhang, Y; Li, M; Gao, X; Chen, Y; Liu, T. Nanotechnology in cancer diagnosis: progress, challenges and opportunities. Journal of Hematology \& Oncology 2019, 12, 137, https://doi.org/10.1186/s13045-019-08333.

11. Javed, A; Ameeduzzafar; Mohammad, Z; Ahmad; Habban, A. Surface-Engineered Cancer Nanomedicine: Rational Design and Recent Progress. Current Pharmaceutical Design 2020, 26, 1181-1190, https://doi.org/10.2174/1381612826666200214110645.

12. Siamof, C.M; Goel, S; Cai, W. Moving Beyond the Pillars of Cancer Treatment: Perspectives From Nanotechnology. Front Chem. 2020, 8, 598100, https://doi.org/10.3389/fchem.2020.598100.

13. Lammers, T; Ferrari, M. The success of nanomedicine, Nano Today 2020, 31, 100853, https://doi.org/10.1016/j.nantod.2020.100853.

14. Jin, C; Wang, K; Oppong-Gyebi, A; Hu, J. Application of Nanotechnology in Cancer Diagnosis and Therapy - A Mini-Review. Int J Med Sci. 2020, 17, 2964-2973, https://doi.org/10.7150/ijms.49801.

15. Martins, J.P; das Neves, J; de la Fuente, M.; Celia, C.; Florindo, H.; Gunday-Tureli, N.; Popat, A.; Santos, J.L.; Sousa, F.; Schmid, R.; Wolfram, J.; Sarmento, B.; Santos, H.A. The solid progress of nanomedicine. Drug Deliv. and Transl. Res. 2020, 10, 726-729, https://doi.org/10.1007/s13346-020-007432.

16. Choi, C.H.J; Xiong, M.P. Nanomedicines Beyond Cancer. Molecular Pharmaceutics 2021, 18, 475-475, https://doi.org/10.1021/acs.molpharmaceut.1c00022.

17. Leon, L; Chung, E.J; Rinaldi, C. A brief history of nanotechnology and introduction to nanoparticles for biomedical applications. Nanoparticles for Biomedical Applications 2020, 1-4, https://doi.org/10.1016/B978-0-12-816662-8.00001-1.

18. Vinardell, M.P; Mitjans, M. Antitumor activities of metal oxide nanoparticles. Nanomaterials 2015, 5, 10041021, https://doi.org/10.3390/nano5021004.

19. Augustine, R; Hasan, A. Emerging applications of biocompatible phytosynthesized metal/metal oxide nanoparticles in healthcare. Journal of Drug Delivery Science and Technology 2020, 56, 1-12, https://doi.org/10.1016/j.jddst.2020.101516.

20. Andra, S; Balu, S.K; Jeevanandham, J. Muthalagu, M.; Vidyavathy, M.; Chan, Y.S.; Danquah, M.K. Phytosynthesized metal oxide nanoparticles for pharmaceutical applications. Naunyn-Schmiedeberg's Arch Pharmacol, 2019, 392, 755-771, https://doi.org/10.1007/s00210-019-01666-7.

21. Nikolova, M.P; Chavali, M.S. Metal Oxide Nanoparticles as Biomedical Materials. Biomimetics 2020, 5, 27, https://doi.org/10.3390/biomimetics5020027. 
22. Długosz, O; Szostak, K; Staroń, A; Pulit-Prociak, J; Banach, M. Methods for Reducing the Toxicity of Metal and Metal Oxide NPs as Biomedicine. Materials 2020, 13, 279, https://doi.org/10.3390/ma13020279.

23. Popov, A.L; Han, B; Ermakov, A.M; Savintseva, I.V; Ermakova, O.N; Popova, N.R.; Shcherbakov, A.B.; Shekunova, T.O.; Ivanova, O.S.; Kozlov, D.A.; Baranchikov, A.E.; Ivanov, V.K. PVP-stabilized tungsten oxide nanoparticles: $\mathrm{p}^{\mathrm{H}}$ sensitive anti-cancer platform with high cytotoxicity, Materials Science and Engineering: C 2020, 108, 110494, https://doi.org/10.1016/j.msec.2019.110494.

24. Mehmood, F; Iqbal, J; Gul, A; Ahmed, W; Ismail, M. Facile synthesis of 2-D Cu doped $\mathrm{WO}_{3}$ nanoplates with structural, optical and differential anti cancer characteristics. Physica E 2017, 88, 188-193, https://doi.org/10.1016/j.physe.2016.12.008.

25. Mehmood, F; Iqbal, J; Jan, T; Mansoor, Q. Structural, photoluminescence, electrical, anti cancer and visible light driven photocatalytic characteristics of Co doped $\mathrm{WO}_{3}$ nanoplates. Vibrational Spectroscopy 2017, 93, 78 - 89, https://doi.org/10.1016/j.vibspec.2017.09.005.

26. Mehmood, F; Iqbal, J; Jan, T; Ahmed, W; Ahmed, W; Arshad, A; Mansoor, Q; Ilyas, S.Z; Ismail, M; Ahmad, I. Effect of Sn doping on the structural, optical, electrical and anti-cancer properties of $\mathrm{WO}_{3}$ nanoplates. Ceramics International 2016, 42, 14334-14341, https://doi.org/10.1016/j.ceramint.2016.04.010.

27. Narumi, H; Katayama, M. Simple topological index: a newly devised index characterizing the topological nature of structural isomers of saturated hydrocarbons. Memoirs of the Faculty of Engineering, Hokkaido University 1984, 16, 209-214, http://hdl.handle.net/2115/38010.

28. Wang, S; Wei, B. Multiplicative Zagreb indices of k-trees. Discrete applied mathematics 2015, 180, 168175, https://doi.org/10.1016/j.dam.2014.08.017.

29. Todeschini, R; Consonni, V. New local vertex invariants and molecular descriptors based on functions of the vertex degrees. Match Commun. Math. Comput. Chem. 2010, 64, 359-372.

30. Gutman, I; Rusci, B; Trinajsti, N; Wilcox, C. F. Jr. Graph theory and molecular orbitals. XII. Acyclic polyenes. Journal of chemical physics 1975, 62, 3399-3405, https://doi.org/10.1063/1.430994.

31. Eliasi, M; Iranmanesh, A; Gutman, I. Multiplicative versions of first Zagreb index. Match Commun. Math. Comput. Chem. 2012, 68, 217-230.

32. Kulli, V. R. Multiplicative Hyper-Zagreb indices and coindices of graphs: computing these indices of some nanostructures. Int. research journal of pure algebra 2016, 6, 342-347.

33. Kulli, V.R; Stone, B; Wang, S; Wei, B. Generalised multiplicative indices of polycyclic aromatic hydrocarbons and benzenoid systems. Z. Naturforsch. A 2017, 72, 573-576, https://doi.org/10.1515/zna2017-0104.

34. Kulli, V.R. Multiplicative connectivity indices of $\mathrm{TUC}_{4} \mathrm{C}_{8}[\mathrm{~m}, \mathrm{n}]$ and $\mathrm{TUC}_{4}[\mathrm{~m}, \mathrm{n}]$ nanotubes. Journal of computer and mathematical sciences 2016, 9, 1047-1605.

35. Bhanumathi, M; Rani, K.E.J. On multiplicative Harmonic index, multiplicative ISI index and multiplicative $\mathrm{F}$ index of $\mathrm{TUC}_{4} \mathrm{C}_{8}[\mathrm{~m}, \mathrm{n}]$ and $\mathrm{TUC}_{4}[\mathrm{~m}, \mathrm{n}]$ nanotubes. Int. j. recent trends life sci. math. 2017, 4, 1-8.

36. Mobia, G. On F-polynomial, multiple and hyper F-index of some molecular graphs. Bulletin of Mathematical Sciences and Applications 2018, 20, 36-43, https://doi.org/10.18052/www.scipress.com/BMSA.20.36.

37. Kwun, Y.C; Virk, A.R; Nazeer, W; Rehman, M.A; Kang, S.M. On the multiplicative degree-based topological indices of silicon-carbon $\mathrm{Si}_{2} \mathrm{C}_{3}-\mathrm{I} \quad[\mathrm{p}, \mathrm{q}]$ and $\mathrm{Si}_{2} \mathrm{C}_{3}-\mathrm{II}$ [p,q]. Symmetry 2018, 10, https://doi.org/10.3390/sym10080320.

38. Bhanumathi, M; Rani, K.E.J. On multilplicative Sum connectivity index, multilplicative Randic index and multilplicative Harmonic index of some Nanostar Dendrimers. International Journal of Engineering Science, Advanced Computing and Bio-Technology 2018, 9, 52-67, https://doi.org/10.26674/ijesacbt/2018/49410.

39. Mehdi, E; Iranmanesh, A. On ordinary generalized geometric-arithmetic index. Applied Mathematics Letters 2011, 24, 582-587, https://doi.org/10.1016/j.aml.2010.11.021.

40. Bhanumathi, M; Rani, K.E.J. On Some Multiplicative Topological Indices. Int. j. recent trends life sci. math. 2017, 4, 9-19.

41. Duraisami, M.S; Parasuraman, K. On certain degree based Zagreb and Randić indices for cubic tungsten trioxide $[p, q, r]$ nanomultilayer. Malaya Journal of Matematik 2020, 8, 1562-1573, https://doi.org/10.26637/MJM0804/0039.

42. Duraisami, M.S; Parasuraman, K. Computational analysis of some degree based topological indices of cubic structured tungsten trioxide $[l, m, n]$ nanomultilayer. Nanosystems: Phys. Chem. Math. 2020, 11, 501-509, https://doi.org/10.17586/2220-8054-2020-11-5-501-509. 